NP9 (continued)

community, family-based workshop curriculum to prevent childhood obesity and promote healthy nutrition and lifestyle behaviors among low-income, low-literacy Hispanic-heritage families in five different locations: California, Illinois, Iowa, Puerto Rico, and Texas.

Description: AC2 is a multi-state, randomized-controlled trial for Mexican and Puerto Rican families. The experimental component includes the RCT with six-week workshop on nutrition, family routines, and physical activity. To date, 285 families have participated. In addition, this project facilitates engagement and education of university students and, working with Extension, contributes to improve outreach and education for Hispanic families. To date, 126 college students and 11 graduate students have participated in the AC2 program.

Evaluation: The presentation will focus on the impact of adaptations to the AC2 curricula (culturally/regionally) across the country among Hispanic groups with different cultural histories and social realities. We will present new materials designed to promote nutrition education, healthy lifestyle and wellness in the Hispanic-heritage community. Our team strides to empower faculty and students in redesigning and developing new evidence-based outreach materials to respond to the immediate needs of the community.

Conclusion and Implications: Attaing health equity is a far reach public health goal under the current high prevalence of obesity and nutrition-related disorders in racial and ethnic minority groups. We found that introduction of the simple concept of "más o menos" (more or less) that focus on changes to increase healthier lifestyles and reduce negative or restrictive behaviors has had a positive impact. To establish a sustainable effort of our "Abriendo Caminos" program, we seek to facilitate more activities that will bridge communities and extension services to better respond to the requests of individuals and families.

Funding: 2015-68001-23248.

\section{NP10 Obesity Risk, Parenting and Diet Quality Tools for Hispanic Families with Preschoolers: EFNEP, Head Start, Medical Clinic-Year 4}

Marilyn Townsend,PhD, RD, mstownsend@ucdavis.edu, University of California, Davis, 1 Shields Ave, Nutrition Department Meyer Hall, Davis, CA 95616; Mical Shilts, $P h D$, California State University Sacramento; Lenna Ontai, $P h D$, University of California, Davis; Cristiana Drake, PhD, University of California, Davis; Louise Lanoue, PhD, University of California, Davis; Dennis Styne, MD, University of California, Davis Medical Center; Nancy Keim, PhD, USDA ARS Western Human Nutrition Research Center; Karina Díaz Rios, PhD, University of California, Merced; Katherine Panarella, MPH, University of California Agriculture and Natural Resources

Objectives: To validate two pediatric obesity risk assessment tools for low-income Spanish speaking parents and one diet quality tool; determine the feasibility of EFNEP embedded in a medical clinic; coordinate an AFRI obesity grant program journal supplement.

Description: The focus of year four (Y4) was to complete participant data collection and entry to validate assessment tools. Enrollment for the EFNEP intervention concluded with post surveys and in-person interviews administered after each of 21 intervention rounds.

Evaluation: Hispanic $(>99 \%)$ parents $(n=239)$ from WIC or Head Start completed the five data collection points and a blood sample ( $\mathrm{n}=169$ children). Children were classified as being overweight (10\%) or obese $(16 \%)$. Children in the highest BMI percentile-for-age quartile have significantly higher lipid $(229 \pm 82)$, and metabolic $(118 \pm 33)$ indices, and larger waist circumference $(58.8 \pm$ 5.7) than children in the lowest BMI percentile-for-age quartile (188 $\pm 95,95 \pm 38,49.9 \pm 2.6$, respectively). A sample of 60 families were videotaped at mealtime and all of the videotapes have been coded for parent behaviors and $20 \%$ for child behaviors. One-hundred and five parents attended at least one EFNEP session who were referred by their child's pediatrician. All parents engaged in setting nutrition and parenting goals and 71 parents were interviewed to assess the relevance of Motivational Modeling \& feasibility of attending EFNEP intervention. In addition, cultural adaptation and design were completed for Mis Vegetales, a vegetable variety tool to measure diet quality. The HK website was also updated to include Spanish language versions of Healthy Kids (HK) and My Child at Meal Time and the newly validated HK 19-item tool http://healthykids.ucdavis.edu/. Journal supplement planning began with communication to project directors and three journals were contacted for comparison bids.

Conclusion and Implications: Products and findings can support efforts to reduce childhood obesity risk in low-income Spanish-speaking families by providing valid tools to identifying risky nutrition and parenting behaviors and illustrating their utility in expanding EFNEP's reach to medical clinics.

Funding: 2015-68001-23280.

\section{NP11 Measuring Parent Food-Related Behaviors with Spanish-Speaking Parents of Preschool Aged Children: Reliability and Validation of Mi Niño a la Hora de Comer-Year 4}

Lenna Ontai,PhD, lontai@ucdavis.edu, University of California, Davis, Department of Human Ecology, One Shields Ave, Davis, CA 95616; Karina Diaz Rios, PhD, RDN, University of California, Merced; Louise Lanoue, PhD, University of California, Davis; Marilyn Townsend, PhD, $R D N$, University of California, Davis; Mical Shilts, PhD, California State University, Sacramento

Objective: Present initial reliability results of the Mi Nino scale and validation of scale responses with mealtime observations to determine whether it captures parent food-related behaviors in low-literacy, Spanish-speaking parents of preschool children. 